\title{
ANTIOXIDANT AND XANTHINE OXIDASE INHIBITORY PROPERTIES AND LC-MS/MS IDENTIFICATION OF COMPOUNDS OF ETHANOLIC EXTRACT FROM MULBERRY LEAVES
}

\author{
Ling Wan, Gang Chen ${ }^{\bowtie}$, SuPing Jian, Xiao Jie Yin, HongLin Zhu
}

State Key Laboratory of Food Science and Technology, Nanchang University Xuefu Av. 999, Nanchang 330047, Jiangxi Province, China

\begin{abstract}
Background. Xanthine oxidase (XO) enzyme inhibitors are used to treat hyperuricemia. Certain natural substances have been reported to be strong inhibitors of xanthine oxidase. The purpose of this study was to evaluate the antioxidant activity and XO inhibition effect of ethanolic extract from mulberry leaves.

Material and methods. The chemical composition of Mulberry leaf ethanolic extract (MLEE) was identified by the LC-MS/MS method. Antioxidant activity was measured by three different assays (i.e. superoxide, hydrogen peroxide, and hydroxyl radicals assays). The inhibitory effect on XO and its inhibitory mechanism were investigated through the testing of inhibition kinetics and inhibition rate.

Results. MLEE showed significant antioxidant activity in the superoxide, hydrogen peroxide, and hydroxyl radicals assays $\left(\mathrm{IC}_{50}\right.$ of $0.33 \pm 0.006 \mathrm{mg} / \mathrm{mL}, 45 \pm 0.8 \mu \mathrm{g} / \mathrm{mL}$, and $2.54 \pm 0.05 \mathrm{mg} / \mathrm{mL}$ for each assay respectively). The effects of XO inhibitory activity showed that MLEE was a reversible and competitive inhibitor with $\mathrm{IC}_{50}$ values of $1104.76 \pm 7.1 \mu \mathrm{g} / \mathrm{mL}$. Eleven compounds, including six flavonoids and five phenolic acids, were identified.

Conclusion. MLEE has been shown to exhibit antioxidant activity and XO inhibitory effect, which provides a new insight into the properties of mulberry leaves and their potential future applications as a natural antigout drug.
\end{abstract}

Keywords: mulberry leaves, antioxidant, xanthine oxidase, LC-MS/MS

\section{INTRODUCTION}

Mulberry (Morus alba L.), which belongs to the Moraceae family, has been widely cultivated in many Asian countries, including China and Japan, and its leaves are used in traditional Chinese herbal medicine to promote urination, lower blood pressure and other diseases (Katsube et al., 2009; Yang et al., 2014). As mulberry leaves possess many active constituents and pharmacological efficacy, they have prospective applications in the food and pharmaceutical industries (Thabti et al., 2012; Yang et al., 2017). Flavonoids and polyphenols are natural active constituents, and many important bioactive functions are related to them (Yang et al., 2014). Many experiments have shown that they demonstrate antioxidant, anti-inflammatory,

Funding Source Declaration. Financial support from State Key Laboratory of Food Science and Technology, Nanchang University.

$\otimes_{\text {Zn_chengang@163.com }}$ 
anticancer and anti-microbial activities and can act as modulators of the activities of enzymes such as XO (Bogucka-Kocka et al., 2016; Danihelová et al., 2012). Moreover, mulberry leaves consist of rutin, isoquercetin, astragalin, which have been shown to be effective antioxidants and XO inhibitors (Chiang et al., 1994; Masuoka et al., 2012). Nevertheless, the XO inhibitory effect of ethanolic extract from mulberry leaves has not been adequately investigated.

Xanthine oxidase (XO) is a critical enzyme involved in purine metabolism, and is a terminal enzyme that catabolizes human purines, catalyzes hypoxanthine to produce xanthine, and then produces uric acid, which could also directly catalyze xanthine to produce uric acid (Jayaraj et al., 2014). Reactive oxygen (ROS), superoxide and hydrogen peroxide are produced by this oxidative reaction (Sahin, 2016). Not only is uric acid pro-inflammatory to vascular cells in the body, but sustained over-production can also cause the deposition of urate monohydrate crystals in human synovial joints and other tissues, which eventually leads to the gout (Kubota et al., 2016; Liu et al., 2016; Nile et al., 2017). Patients with gout often have other comorbidities, including hyperlipidemia, diabetes and hypertension, which have significant adverse effects on their quality of life and health (Ren et al., 2016). The clinical treatment and prevention of gout are achieved using drugs to inhibit the activity of $\mathrm{XO}$ and reduce the production of uric acid. For instance, allopurinol and fluorconastine are effective XO inhibitors and are used as the main drugs for the treatment of gout. However, side effects including hematological myelosuppression, liver, kidney and gastrointestinal toxicity, and allergic reactions have been frequently reported (Wang et al., 2015). Therefore, it is very important to find an effective and safe XO inhibitor for pharmaceutical applications.

Hence, the aim of this study was to prove that ethanolic extract from mulberry leaves can inhibit XO activity, and further decipher their underlying inhibitory mechanisms. In addition, chemical compositions were qualitatively determined by LC-MS/MS. Our work may promote the economic value of mulberry leaves as a potential pharmaceutical ingredient for applications to treat gout.

\section{MATERIALS AND METHODS}

\section{Reagents}

Xanthine oxidase, allopurinol and xanthine were obtained from Solarbio (Beijing, China). NBT, NADH, and PMS were obtained from Aladdin (Shanghai, China). Other solvents and chemicals were of analytical reagent grade.

Mulberry leaves were collected from the MeiLing mountain of Jiangxi, China, in April 2017. The leaves were identified by the botanist LiPing Luo from Nanchang University, China.

\section{Preparation of plant extract}

For the preparation of the plant extract, $100 \mathrm{~g}$ of mulberry leaves were chopped into pieces and then extracted twice by refluxing with $80 \%$ ethanol (1:30, $\mathrm{w} / \mathrm{v})$ for $70 \mathrm{~min}$ in a sonication extractor $(200 \mathrm{~W})$. After filtration, the solutions were concentrated using a rotary evaporator. It was precipitated four times with 95\% ethanol and purified using an AB-8 resin column. Finally, MLEE powder was obtained by freeze-drying.

\section{Determination of total polyphenols and flavonoids content}

The polyphenol content in MLEE was measured by Folin-Ciocalteau method (Simirgiotis et al., 2013). The total flavonoid content in MLEE was determined according to the previously described method with some modifications. $1.0 \mathrm{ml}$ of the sample solution was added to $1 \mathrm{ml}$ of $\mathrm{NaNO}_{2}$ solution $(1: 20, \mathrm{w} / \mathrm{v})$. After 6 minutes, $1 \mathrm{ml}$ of $\mathrm{Al}\left(\mathrm{NO}_{3}\right)_{3}(1: 10, \mathrm{w} / \mathrm{v})$ was added and kept at room temperature for 6 minutes. Finally, $4 \mathrm{ml}$ of $\mathrm{NaOH}(1 \mathrm{M})$ was added to the solution and then made up to $10 \mathrm{ml}$ with $60 \%$ ethanol. After standing for 12 minutes, absorbance was read at $510 \mathrm{~nm}$ (Hu et al., 2016).

\section{LC-MS/MS conditions}

LC-MS/MS analysis was conducted with a Hybrid Quadrupole-TOF LC/MS/MS Mass Spectrometer TripleTOF 5600+ (AB Sciex Agilent Technologies, Germany) equipped with an orthogonal electrospray ionization source (ESI) in the negative ion mode. The conditions were as following: the mobile phase consisted of $0.1 \%$ formic acid in water (solvent A) and acetonitrile (solvent B). Mass spectrometer 
Wan, L., Chen, G., Jian, S., Yin, H. J., Zhu, H. (2018). Antioxidant and xanthine oxidase inhibitory properties and LC-MS/MS identification of compounds of ethanolic extract from Mulberry leaves. Acta Sci. Pol. Technol. Aliment., 17(4), 313-319. http://dx.doi. org/10.17306/J.AFS.2018.0587

electrospray capillary voltage was $4.5 \mathrm{kV}$, Heat Compensation Flow nebulizer pressure was 50 psi, collision energy (the first order was $10 \mathrm{eV}$, the second order was $30 \pm 15 \mathrm{VeV}$ ), fragmentor voltage was $135 \mathrm{~V}$ and the mass to charge ratio $(\mathrm{m} / \mathrm{z})$ ranged from 70 $1250 \mathrm{~m} / \mathrm{z}$ using $550^{\circ} \mathrm{C}$ drying gas $\left(\mathrm{N}_{2}\right)$ temperature of and $6 \mathrm{~L} / \mathrm{min}$ drying gas flow (He et al., 2013).

\section{Superoxide radical scavenging activity}

The scavenging effect of the superoxide radical was evaluated by the NADH/PMS system according to the previously described method (Xing et al., 2006). The reaction mixture, containing various concentrations of sample, NBT (300 $\mu \mathrm{mol} / \mathrm{L})$, NADH $(456 \mu \mathrm{mol} / \mathrm{L})$, and PMS $(60 \mu \mathrm{mol} / \mathrm{L})$ in Tris- $\mathrm{HCl}$ buffer $(16 \mathrm{mmol} / \mathrm{L}$, $\mathrm{pH} 8.0$ ), was incubated at room temperature for $5 \mathrm{~min}$.

\section{Hydrogen peroxide $\left(\mathrm{H}_{2} \mathrm{O}_{2}\right)$ scavenging assay}

The scavenging activity of hydrogen peroxide was determined according to the previously described method with some modifications (Liu et al., 2009). Briefly, $2 \mathrm{~mL}$ of different concentrations of MLEE were mixed with $2 \mathrm{~mL}$ of $\mathrm{H}_{2} \mathrm{O}_{2}(800 \mu \mathrm{mol} / \mathrm{L})$ prepared in a potassium phosphate buffer ( $\mathrm{pH}$ 7.4) and the solution was incubated at room temperature for $10 \mathrm{~min}$.

\section{Hydroxyl radical $(\mathrm{OH})$ scavenging activity}

Hydroxyl radical $(\mathrm{OH})$ scavenging activity was determined according to the previously described method with slight modifications (Naheed et al., 2017). Briefly, $1 \mathrm{~mL}$ of $\mathrm{FeSO}_{4}(9 \mathrm{mmol} / \mathrm{L})$ was added to a microfuge tube. Then, $1 \mathrm{~mL}$ of different concentrations of MLEE and $1 \mathrm{~mL}$ salicylic acid $(9 \mathrm{mmol} / \mathrm{L})$ were added. The final volume of reaction mixture was added to $1 \mathrm{~mL}$ of $\mathrm{H}_{2} \mathrm{O}_{2}$ $(8.8 \mathrm{mmol} / \mathrm{L})$ solution and incubated at $37^{\circ} \mathrm{C}$ for $30 \mathrm{~min}$.

\section{Xanthine oxidase inhibitory assay}

Xanthine oxidase inhibitory activity was determined as described previously (Jayaraj et al., 2014), with some modifications. Briefly, $1 \mathrm{ml}$ of different concentrations of samples and $2.9 \mathrm{~mL}$ phosphate buffer $(\mathrm{pH} 7.5)$ and $0.1 \mathrm{~mL}(0.1 \mathrm{unit} / \mathrm{mL})$ of bovine milk XO were mixed and reacted at $25^{\circ} \mathrm{C}$ for 15 minutes. Then, $2 \mathrm{ml}(150$ $\mu \mathrm{mol} / \mathrm{L}$ ) xanthine solution was added into the mixture to trigger a reaction, and incubated at $25^{\circ} \mathrm{C}$ for 30 minutes. $1 \mathrm{~mL}$ of $1 \mathrm{~N} \mathrm{HCl}$ was added to terminate the reaction, and the spectrophotometer was measured at $295 \mathrm{~nm}$.

\section{Analysis of inhibitory kinetics}

In order to determine the inhibition type of MLEE, Lineweaver-Burk plot analysis was performed. MLEE was tested by the method of inhibiting the $\mathrm{XO}$, and plots were obtained at several concentrations of MLEE using different concentrations of XO (Zhang et al., 2017).

\section{Statistical analysis}

The result were expressed as mean \pm SD values $(n=3)$ and analyzed by one-way ANOVA using Origin 8.5 software. $p<0.05$ was considered significant.

\section{RESULTS AND DISCUSSION}

\section{Phytochemical analysis of MLEE}

Polyphenols and flavonoids were the main components of MLEE, the respective contents of which were $42.6 \%$ and $33.8 \%$. Eleven compounds, including six flavonoids and five phenolic acids, were detected, and their chemical formulas and mass were summarized in Table 1. This also included retention times, $[\mathrm{M}-\mathrm{H}]^{-}$ $(\mathrm{m} / \mathrm{z}), \mathrm{MS}^{2}$ ions and identified compounds. The main parameters of the identified compounds are shown in Table 1.

\section{Antioxidant activity}

Superoxide radical produced in vivo is a very harmful factor to cellular components, and can result in the formation of $\mathrm{H}_{2} \mathrm{O}_{2}$ via a dismutation reaction, which has many undesirable effects on the human body (Kumaran and Karunakaran, 2007). The data for the superoxide radical scavenging effect of MLEE and ascorbic acid is shown in Table 2. The assay results prove that MLEE has good scavenging activity against superoxide radical $\left(\mathrm{IC}_{50}=0.33 \pm 0.006 \mathrm{mg} / \mathrm{mL}\right)$, which was lower than ascorbic acid $\left(\mathrm{IC}_{50}=0.27 \pm 0.004 \mathrm{mg} / \mathrm{mL}\right)$ but higher than vitamin $\mathrm{E}\left(\mathrm{IC}_{50}=0.96 \pm 0.03 \mathrm{mg} / \mathrm{mL}\right)$.

Hydrogen peroxide is not a free radical, but can cross membranes and may slowly oxidize a number of biomolecules and form hydroxyl in the presence of metal ions. Hence, metal chelating and hydrogen peroxide scavenging processes are important for living organisms (Gulcin et al., 2003). The result of the superoxide radical scavenging effect of MLEE and ascorbic acid is shown in Table 2. The MLEE had better hydrogen peroxide scavenging ability exhibited 
Wan, L., Chen, G., Jian, S., Yin, H. J., Zhu, H. (2018). Antioxidant and xanthine oxidase inhibitory properties and LC-MS/MS identification of compounds of ethanolic extract from Mulberry leaves. Acta Sci. Pol. Technol. Aliment., 17(4), 313-319. http://dx.doi. org/10.17306/J.AFS.2018.0587

Table 1. Eleven compounds identified by LC-MS/MS

\begin{tabular}{ccclcl}
\hline Number & $\begin{array}{r}\mathrm{Rt} \\
\mathrm{mi}\end{array}$ & $\begin{array}{c}{[\mathrm{M}-\mathrm{H}]^{-}} \\
\mathrm{m} / \mathrm{z}\end{array}$ & Formula & $\mathrm{MS}^{2}$ ions & \multicolumn{1}{c}{ Identified compounds } \\
\hline 1 & 4.53 & 179.0353 & $\mathrm{C}_{9} \mathrm{H}_{8} \mathrm{O}_{4}$ & 135 & caffeic acid \\
2 & 3.35 & 325.0933 & $\mathrm{C}_{15} \mathrm{H}_{18} \mathrm{O}_{8}$ & 163,119 & p-coumaric acid glycoside \\
3 & 2.11 & 353.0880 & $\mathrm{C}_{16} \mathrm{H}_{18} \mathrm{O}_{9}$ & $191,179,135$ & chlorogenic acid \\
4 & 4.65 & 385.1144 & $\mathrm{C}_{17} \mathrm{H}_{22} \mathrm{O}_{10}$ & 223 & sinapic acid hexoside \\
5 & 1.63 & 515.1209 & $\mathrm{C}_{25} \mathrm{H}_{24} \mathrm{O}_{12}$ & $353,191,179$ & dicaffeoyl-quinic acid \\
6 & 9.14 & 447.0946 & $\mathrm{C}_{21} \mathrm{H}_{20} \mathrm{O}_{11}$ & 285,255 & astragalin \\
7 & 8.03 & 463.0892 & $\mathrm{C}_{21} \mathrm{H}_{20} \mathrm{O}_{12}$ & 300,255 & isoquercitrin \\
8 & 7.58 & 609.1486 & $\mathrm{C}_{27} \mathrm{H}_{30} \mathrm{O}_{16}$ & 300 & rutin \\
9 & 8.64 & 593.1532 & $\mathrm{C}_{27} \mathrm{H}_{30} \mathrm{O}_{15}$ & 285 & kaempferol-rhamnoside-hexoside \\
10 & 10.03 & 533.0959 & $\mathrm{C}_{24} \mathrm{H}_{22} \mathrm{O}_{14}$ & 489,285 & kaempferol-malonyl-hexoside \\
11 & 10.03 & 489.1056 & $\mathrm{C}_{23} \mathrm{H}_{22} \mathrm{O}_{12}$ & 285 & kaempferol-acetyl-hexoside \\
\hline
\end{tabular}

Table 2. Antioxidant activity evaluation of the MLEE and ascorbic acid

\begin{tabular}{lccc}
\hline & $\begin{array}{c}\mathrm{IC}_{50} \text { superoxide radical } \\
\mathrm{mg} / \mathrm{mL}\end{array}$ & $\begin{array}{c}\mathrm{IC}_{50} \mathrm{H}_{2} \mathrm{O}_{2} \\
\mu \mathrm{g} / \mathrm{mL}\end{array}$ & $\begin{array}{c}\mathrm{IC}_{50} \text { hydroxyl radical } \\
\mathrm{mg} / \mathrm{mL}\end{array}$ \\
\hline MLEE & $0.33 \pm 0.006$ & $45 \pm 0.8$ & $2.54 \pm 0.05$ \\
Ascorbic acid & $0.27 \pm 0.004$ & $80.46 \pm 1.4$ & $0.37 \pm 0.02$ \\
Vitamin E & $0.96 \pm 0.03$ & $110.56 \pm 3.2$ & $1.83 \pm 0.06$ \\
\hline
\end{tabular}

All values are expressed as mean \pm standard deviation $(n=3)$.

the lowest $\mathrm{IC}_{50}$ value at $45 \pm 0.8 \mu \mathrm{g} / \mathrm{mL}$, which was stronger than ascorbic acid $\left(\mathrm{IC}_{50}=80.46 \pm 1.4 \mu \mathrm{g} / \mathrm{mL}\right)$ and vitamin $\mathrm{E}\left(\mathrm{IC}_{50}=110.56 \pm 3.2 \mathrm{mg} / \mathrm{mL}\right)$. Thus, the MLEE was shown to have potential as a kind of hydrogen peroxide scavenger. The hydroxyl radical, a highly toxic radical, can cause oxidative damage to biological macromolecules including lipids, proteins and nucleic acids (Ozyürek et al., 2008). As shown in Table 2, the hydroxyl scavenging ability of MLEE and its fractions increased in a dose-dependent manner. In addition, ascorbic acid showed excellent scavenging activity. Clearly, ascorbic acid could effectively scavenge hydroxyl radicals with an $\mathrm{IC}_{50} 0.37 \pm 0.02$, and MLEE was also observed to have scavenging activity with an $\mathrm{IC}_{50}$ value of $2.54 \pm 0.05 \mathrm{mg} / \mathrm{mL}$ close to vitamin $\mathrm{E}$.

\section{Xanthine oxidase inhibition}

As shown in Figure 1, MLEE negatively correlated with the relative activity of $\mathrm{XO}$, and inhibited $\mathrm{XO}$ activity in a dose-dependent manner. $\mathrm{The} \mathrm{IC}_{50}$ value of MLEE was $1104.76 \pm 7.1 \mu \mathrm{g} / \mathrm{mL}$, whereas that of allopurinol was $1.19 \pm 0.04 \mu \mathrm{g} / \mathrm{mL}$. Although allopurinol showed a stronger inhibitory rate than MLEE, many previous studies have demonstrated that allopurinol can cause many strong side effects (Wang et al., 2017). Therefore, drugs with less toxic side effects are in urgent need of development. Taking all of these factors into consideration, we can come to the conclusion that MLEE contains XO inhibitors and merits further research. 


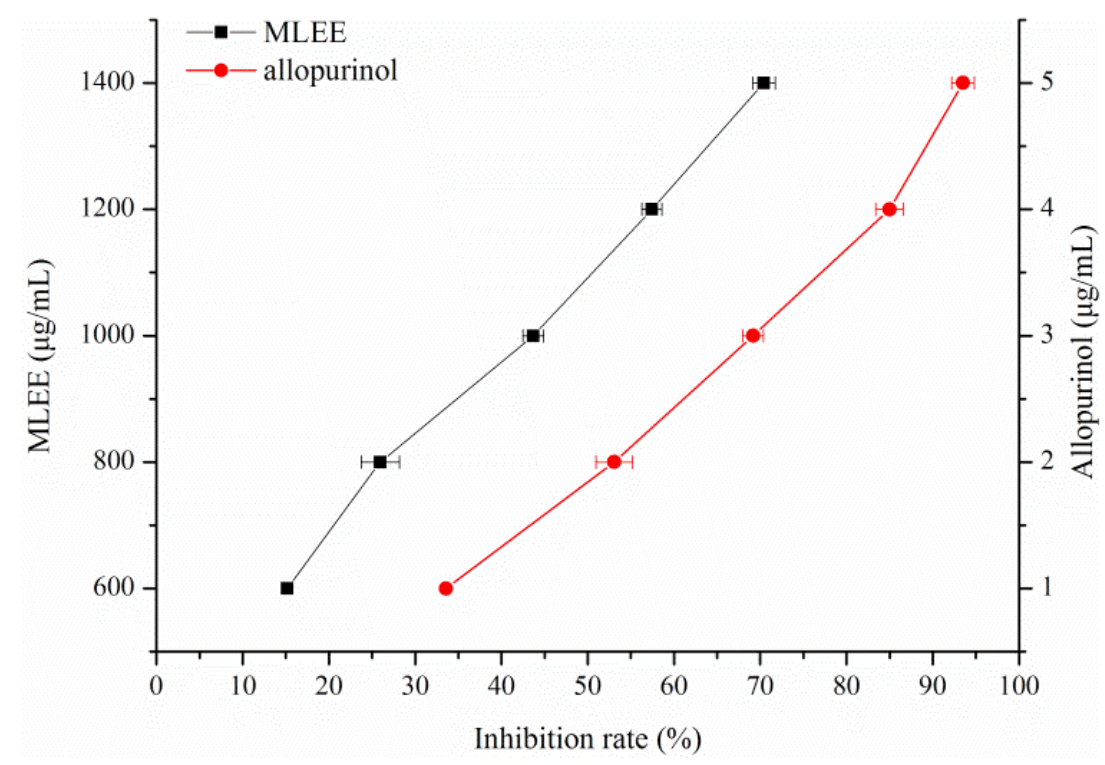

Fig. 1. XO inhibition rate by MLEE and allopurinol

\section{Determination of inhibitory type}

The inhibition mechanism of MLEE was investigated based on the Lineweaver-Burk plot (Fig. 2A). From curves 1 to 5 , as the MLEE concentration increases, the slope of the straight line decreases, and all lines pass through the origin, indicating that MLEE causes the reversible inhibition of XO. The catalytic activity of $\mathrm{XO}$ was reduced by affecting the synthesis of the enzyme-substrate complex and the decomposition of the enzyme-product complex (Phan et al., 2013). To investigate the kinetics of the enzyme in the presence of MLEE, the Lineweaver-Burk plot equation
A

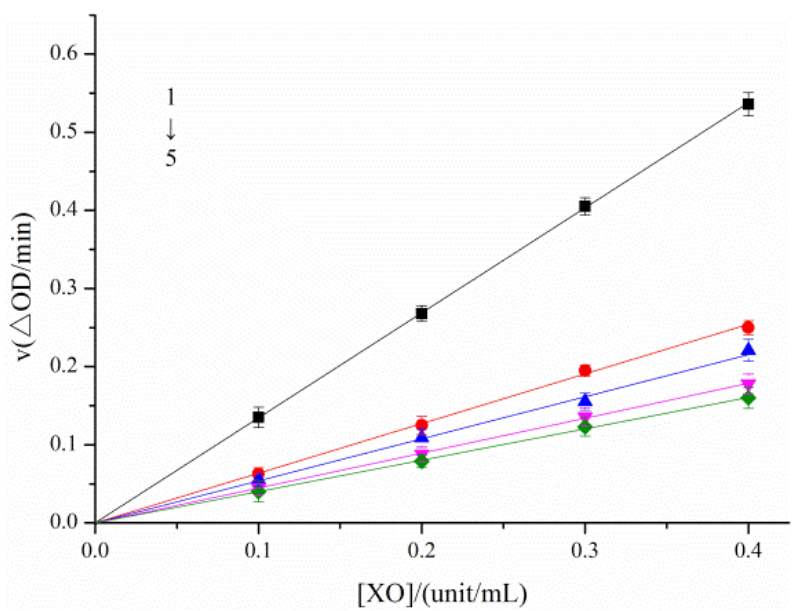

B

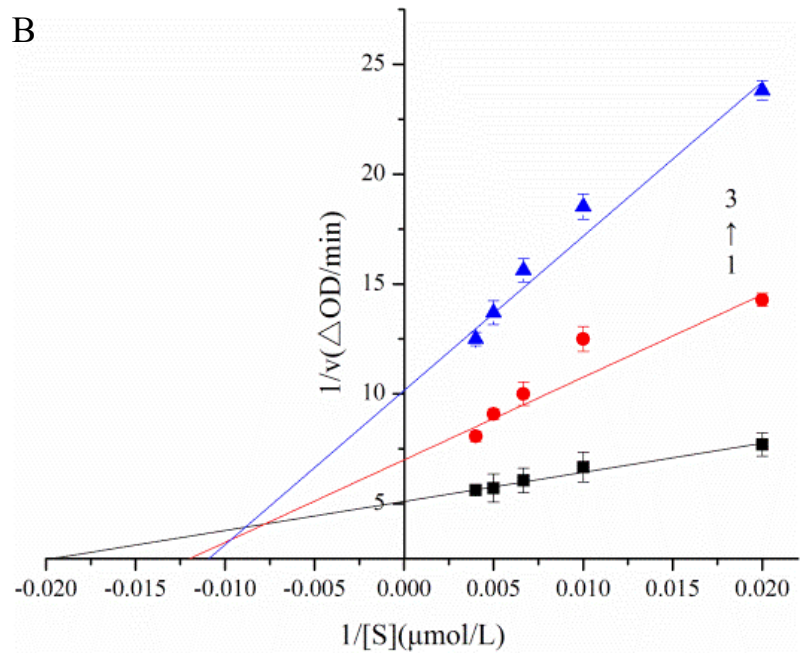

Fig. 2. (A) reversible results plots for MLEE: $\mathrm{c}$ (xanthine) $-150 \mu \mathrm{mol} / \mathrm{L}$, c MLEE) $-0,0.2,0.4,0.6,0.8 \mathrm{mg} / \mathrm{mL}$ for curve $1-5$ respectively. (B) Lineweaver-Burk double reciprocal plots for MLEE: $\mathrm{c}(\mathrm{XO})-0.1$ units/mL, c(MLEE) $-0,0.5,1 \mathrm{mg} / \mathrm{mL}$ for curve $1-3$, respectively 
Wan, L., Chen, G., Jian, S., Yin, H. J., Zhu, H. (2018). Antioxidant and xanthine oxidase inhibitory properties and LC-MS/MS identification of compounds of ethanolic extract from Mulberry leaves. Acta Sci. Pol. Technol. Aliment., 17(4), 313-319. http://dx.doi. org/10.17306/J.AFS.2018.0587

in double reciprocal form was used and the results were displayed in Figure 2B. All of the data lines with different slopes and intercepts intersected in the second quadrant, indicating that MLEE was a mixed-type inhibitor against the formation of uric acid. Furthermore, MLEE may have a single inhibition site or a single class of inhibition sites on XO (Phan et al., 2013; Xi et al., 2016; Zhang et al., 2018).

\section{CONCLUSIONS}

In this study, we analyzed polyphenol and flavonoid content, antioxidant activity, XO inhibitory effect, and inhibitory mechanisms of MLEE. The results suggest that MLEE has significant antioxidant and XO inhibitory properties. The inhibition type of MLEE on XO was reversible and mixed-type inhibition of MLEE compounds was simultaneously determined using a validated LC-MS/MS method. This finding shows that mulberry leaves contain a variety of compounds, many of which could inhibit $\mathrm{XO}$, such as rutin, isoquercetin, and astragalin. Hence, we came to the conclusion that MLEE contains bioactive compounds which could make a potential contribution to the development of new anti-gout drugs and other oxidative stress-related conditions in humans. However, more studies in vivo are needed to determine appropriate candidates for clinical investigation.

\section{ACKNOWLEDGEMENTS}

The authors wish to thank Professor Baoping Ji from China Agricultural University for his valuable suggestions and technical support.

\section{REFERENCES}

Bogucka-Kocka, A., Zidorn, C., Kasprzycka, M., Szymczak, G., Szewczyk, K. (2016). Phenolic acid content, antioxidant and cytotoxic activities of four Kalanchoë species. Saudi J. Biol. Sci., 25(4), 622-630. http:// dx.doi.org/10.1016/j.sjbs.2016.01.037

Chiang, H. C., Lo, Y. J., Lu, F. J. (1994). Xanthine oxidase inhibitors from the leaves of Alsophila spinulosa (Hook) Tryon. J. Enzym. Inhibit., 8(1), 61.

Danihelová, M., Ová, J. V., Turdík, E. (2012). Lipophilization of flavonoids for their food, therapeutic and cosmetic applications. Acta Chim. Slov., 5(1), 59-69.
Gulcin, İ., Buyukokuroglu, M. E., Kufrevioglu, O. I. (2003). Metal chelating and hydrogen peroxide scavenging effects of melatonin. J. Pineal Res., 34(4), 278-281.

He, J., Feng, Y., Ouyang, H. Z., Yu, B., Chang, Y. X., Pan, ..., Gao, X. M. (2013). A sensitive LC-MS/MS method for simultaneous determination of six flavonoids in rat plasma: Application to a pharmacokinetic study of total flavonoids from mulberry leaves. J. Pharm. Biomed. Anal., 84(10), 189-195.

Hu, Q., Jie, Y., Yang, W., Kimatu, B. M., Yong, F., Ning, M., Fei, P. (2016). Identification of flavonoids from Flammulina velutipes and its neuroprotective effect on pheochromocytoma-12 cells. Food Chem., 204, 274-282.

Jayaraj, P., Mathew, B., Parimaladevi, B., Ramani, V. A., Govindarajan, R. (2014). Isolation of a bioactive flavonoid from Spilanthes calva D.C. in vitro xanthine oxidase assay and in silico study. Biomed. Prevent. Nutr., 4(4), 481-484. https://doi.org/10.1016/j.bionut.2014.07.005

Katsube T., Tsurunaga, Y., Sugiyama, M., Furuno, T., Yamasaki, Y. (2009). Effect of air-drying temperature on antioxidant capacity and stability of polyphenolic compounds in mulberry (Morus alba L.) leaves. Food Chem., 113(4), 964-969. https://doi.org/10.1016/j.foodchem. 2008.08.041

Kubota, Y., Mcadams-Demarco, M., Folsom, A. R. (2016). Serum uric acid, gout, and venous thromboembolism: The atherosclerosis risk in communities study. Thromb. Res., 144, 144-148.

Kumaran, A., Karunakaran, R. J. (2007). In vitro antioxidant activities of methanol extracts of five Phyllanthus species from India. LWT - Food Sci. Technol., 40(2), 344-352. https://doi.org/10.1016/j.lwt.2005.09.011

Liu, J., Sun, H., Dong, F., Xue, Q., Wang, G., Qin, S., Guo, Z. (2009). The influence of the cation of quaternized chitosans on antioxidant activity. Carbohydr. Polym., 78(3), 439-443.

Liu, S., Perez-Ruiz, F., Miner, J. N. (2016). Patients with gout differ from healthy subjects in renal response to changes in serum uric acid. Joint Bone Spine, 84(2), 183.

Masuoka, N., Matsuda, M., Kubo, I. (2012). Characterisation of the antioxidant activity of flavonoids. Food Chem., 131(2), 541-545. http://dx.doi.org/10.1016/j. foodchem.2011.09.020

Naheed, Z., Cheng, Z., Wu, C., Wen, Y., Ding, H. (2017). Total polyphenols, total flavonoids, allicin and antioxidant capacities in garlic scape cultivars during controlled atmosphere storage. Postharv. Biol. Technol., 131, 39-45.

Nile, S. H., Nile, A. S., Keum, Y. S., Sharma, K. (2017). Utilization of quercetin and quercetin glycosides from onion (Allium cepa L.) solid waste as an antioxidant, 
Wan, L., Chen, G., Jian, S., Yin, H. J., Zhu, H. (2018). Antioxidant and xanthine oxidase inhibitory properties and LC-MS/MS identification of compounds of ethanolic extract from Mulberry leaves. Acta Sci. Pol. Technol. Aliment., 17(4), 313-319. http://dx.doi. org/10.17306/J.AFS.2018.0587

urease and xanthine oxidase inhibitors. Food Chem., $235,119-126$.

Ozyürek, M., Bektaşoğlu, B., Güçlü, K., Apak, R. (2008). Hydroxyl radical scavenging assay of phenolics and flavonoids with a modified cupric reducing antioxidant capacity (CUPRAC) method using catalase for hydrogen peroxide degradation. Anal. Chim. Acta, 616(2), 196.

Phan, M. A. T., Wang, J., Tang, J., Yan, Z. L., Ng, K. (2013). Evaluation of $\alpha$-glucosidase inhibition potential of some flavonoids from Epimedium brevicornum. LWT - Food Sci. Technol., 53(2), 492-498. http://dx.doi. org/10.26480/icnmim.01.2018.312.314

Ren, Y. C., Jin, T. B., Sun, X. D., Geng, T. T., Zhang, M. X., Wang, L., Feng, T., ..., Chen, C. (2016). PDK2 and ABCG2 genes polymorphisms are correlated with blood glucose levels and uric acid in Tibetan gout patients. Genet. Molec. Res., 15(1).

Sahin, H. (2016). Honey as an apitherapic product: its inhibitory effect on urease and xanthine oxidase. J. Enzym. Inhib. Med. Chem., 31(3), 490.

Simirgiotis, M. J., Ramirez, J. E., Hirschmann, G. S., Kennelly, E. J. (2013). Bioactive coumarins and HPLC-PDA-ESI-ToF-MS metabolic profiling of edible queule fruits (Gomortega keule), an endangered endemic Chilean species. Food Res. Int., 54(1), 532-543. http://dx.doi. org/10.1016/j.foodres.2013.07.022

Thabti, I., Elfalleh, W., Hannachi, H., Ferchichi, A., Campos, M. D. G. (2012). Identification and quantification of phenolic acids and flavonol glycosides in Tunisian Morus species by HPLC-DAD and HPLC-MS. J. Funct. Foods, 4(1), 367-374.

Wang, Y., Zhang, G., Pan, J., Gong, D. (2015). Novel insights into the inhibitory mechanism of kaempferol on xanthine oxidase. J. Agric. Food Chem., 63(2), 526-534.
Wang, Z., Kwon, S. H., Hwang, S. H., Kang, Y. H., Lee, J. Y., Lim, S. S. (2017). Competitive binding experiments can reduce the false positive results of affinity-based ultrafiltration-HPLC: A case study for identification of potent xanthine oxidase inhibitors from Perilla frutescens extract. J. Chromatogr., B, 1048, 30-37.

Xi, P., Guowen, Z., Yijing, L., Deming, G. (2016). Inhibitory kinetics and mechanism of kaempferol on $\alpha$-glucosidase. Food Chem., 190, 207-215.

Xing, R., Liu, S., Guo, Z., Yu, H., Li, C., Ji, X., ..., Li, P. (2006). The antioxidant activity of glucosamine hydrochloride in vitro. Bioorg. Med. Chem., 14(6), 1706-1709.

Yang, S., Li, Y., Jia, D., Yao, K., Liu, W. (2017). The synergy of Box-Behnken designs on the optimization of polysaccharide extraction from mulberry leaves. Ind. Crops Prod., 99, 70-78.

Yang, Y., Tan, Y. X., Chen, R. Y., Kang, J. (2014). The latest review on the polyphenols and their bioactivities of Chinese Morus plants. J. Asian Nat. Prod. Res., 16(6), 690702. https://doi.org/10.1080/10286020.2014.923405

Zhang, C., Wang, R., Zhang, G., Gong, D. (2018). Mechanistic insights into the inhibition of quercetin on xanthine oxidase. Int. J. Biol. Macromol., 112, 405-412.

Zhang, Z. C., Wang, H. B., Zhou, Q., Hu, B., Wen, J. H., Zhang, J. L. (2017). Screening of effective xanthine oxidase inhibitors in dietary anthocyanins from purple sweet potato (Ipomoea batatas L. Cultivar Eshu No. 8) and deciphering of the underlying mechanisms in vitro. J. Funct. Foods, 36, 102-111. 